\title{
IDENTIFIKASI MATERIAL DAN PROSES PERLAKUAN PANAS LADAM UNTUK KUDA PACU
}

\author{
Muki Satya Permana, Gatot Santoso dan Bambang Heru \\ Program Studi Teknik Mesin Fakuktas Teknik Universitas Pasundan \\ e-mail: mkpermana@yahoo.com/muki.satya@unpas.ac.id
}

\begin{abstract}
Equestrian sport or horse riding is very popular because not only for sports or hobby, but also for entertainment. The performance of the racehorse is largely determined by the suitability of the characteristics of horseshoes material with horse's hooves. This paper describes the identification of materials and heat treatment process of horseshoe made in local and imported products. Previous publication suggests that horseshoe made in foreign countries provides better performance than domestic products, especially in terms of flexibility of horse motion, durability, speed, and lifetime. Therefore, it is necessary to conduct research that emphasizes the observation of material characteristics, manufacturing and heat treatment process as a first step towards the substitution of imported products. A number of observations have been made on the two types of products: macro and micro metallographic observations, heat treatment process analyzes that have been subjected to materials, and mechanical testing. From the test results obtained that imported horseshoe material is low carbon steel with a carbon content of $0.08 \%$, while carbon content for local product is $0.17 \%$. Thus, both from the material side and from the side of manufacturing, including heat treatment process, local horseshoe products still need to be developed.
\end{abstract}

Keywords: Equestrian sport, horseshoes material, horse's hooves, identification of materials and heat treatment process, local and imported products.

\section{PENDAHULUAN}

Ladam adalah besi pelapis yang dipakai oleh kuda untuk melindungi kaki kuda. Olahraga berkuda merupakan entertainment sport yang juga diyakini berpengaruh baik dalam tumbuh kembang anak-anak dan dapat menjadi terapi bagi anak autis [1]. Penelitian penggunaan material ladam sangat meningkat dengan semakin pesatnya olahraga berkuda di dunia [2]. Hal ini sejalan dengan maraknya kejuaraan pacuan kuda tingkat nasional yang digelar khususnya oleh Pordasi (Persatuan Olahraga Berkuda Seluruh Indonesia). Perkembangan material tersebut pada mulanya menggunakan Carbon Steel, kemudian Aluminium, dan yang saat ini dikembangkan adalah Titanium. Pertimbangan pengembangan material-material tersebut ditujukan untuk meningkatkan performa kinerja kuda pacu diimbangi dengan penggunaan material yang lebih ringan dan memiliki fleksibilitas yang lebih tinggi dibandingkan dengan material yang sebelumnya. Saat ini penggunaan material Titanium masih dalam tahap pengembangan dan pengujian [3]. Berkaitan dengan penggunaan dan pemilihan material-material tersebut, seringkali ladam harus diimpor dari luar negeri seperti Australia, China, dan Malaysia. Dari sekian banyak produk impor, ternyata produk buatan Malaysia yang terbuat dari carbon steel dinilai cukup memenuhi persyaratan performa kinerja kuda pacu yang lebih unggul dibandingkan dengan produk China dan produk lainnya [4].

Dewasa ini, kebutuhan ladam yang digunakan untuk keperluan kuda pacu jumlahnya semakin meningkat. Sebuah ladam yang dipasangkan pada setiap kuda hanya berumur enam minggu. Apabila ladam digunakan untuk sebuah kuda selama sesi latihan dalam satu tahun, maka diperlukan ladam sebanyak delapan kali empat buah kaki kuda yaitu sebanyak 32 buah ladam. Data jumlah kuda pacu di Jawa Barat saja pada tahun 2016 adalah sebanyak 302 ekor kuda. Jika kebutuhan ladam per tahun untuk setiap kuda sebanyak 32 buah maka 302 kali 32 membutuhkan ladam sebanyak 9.664. Terlebih lagi apabila kuda yang dilombakan untuk setiap kejuaraan rata-rata sebanyak 300 ekor, maka kebutuhan ladam untuk setiap perlombaan memerlukan ladam sebanyak 300 ekor kali empat kaki yaitu 1.200 buah ladam [5]. Dari data di atas, maka kebutuhan total ladam di seluruh pelosok negeri dapat dihitung dengan mudah dan tentunya akan memerlukan jumlah yang amat banyak. 
Dengan melihat pada sudut pandang kebutuhan produk ladam beserta pakunya yang demikian tinggi maka hal ini merupakan potensi pasar yang perlu dipertimbangkan dan dikembangkan di pasar dalam negeri. Dalam konteks ini, dalam negeri harus mampu mengembangkan dan memproduksi ladam sendiri. Hal ini sejalan dengan program pemerintah yaitu peningkatan kemampuan dalam negeri dalam melakukan substitusi impor. Untuk meningkatkan kualitas dan menaikkan daya saing dalam memanfaatkan pasar yang besar ini, maka diperlukan penelitian dan pengembangan, baik dari segi pengembangan rancangan geometri, material, maupun proses manufakturnya. Industri skala kecil-menengah belum mampu melaksanakannya oleh karena keterbatasan dana, peralatan dan SDM yang dimiliki. Merujuk pada latar belakang tersebut di atas maka masalah yang ingin dipecahkan dalam penelitian ini adalah bagaimana melakukan identifikasi material dan proses perlakuan panas ladam produk impor dan produk lokal.

\section{METODE PENELITIAN}

Sejumlah pengamatan dan pengujian dilakukan melalui beberapa tahapan yakni pengumpulan data ladam lokal dan impor. Ladam lokal adalah buatan Pengrajin Sukabumi, sedangkan ladam impor buatan Australia. Observasi visual diperlukan untuk mengamati dan menandai area yang akan dipotong yang disiapkan untuk berbagai pengamatan dan pengujian seperti pengamatan metalografi, pengujian kekerasan, dan pemeriksaan komposisi kimia.

Sebelum dilakukan pengamatan metalografi, kedua produk ladam dipotong dan dibuat spesimen untuk uji struktur mikro dengan menggunakan resin mounting. Selanjutnya, spesimen diampelas dengan menggunakan grinding machine dengan mesh grid ampelas berturut-turut adalah 80, 120, 240, 400, 600, 800, 1.200, 1.600 dan 2.000. Setelah pengampelasan, proses berikutnya adalah pemolesan spesimen dengan menggunakan kain beludru (polishing) yang dihaluskan dengan bantuan cairan Pasta Alumina 0.1 mikron. Proses terakhir adalah etsa spesimen dengan menggunakan cairan Nital 3\%. Hingga kondisi terakhir ini, spesimen siap untuk dilihat di bawah mikroskop optik cahaya/LOM (Light Optical Microscope). Pengujian selanjutnya adalah pemeriksaan komposisi kimia material ladam dengan menggunakan teknik spektroskopi OES (Optical Emission Spectroscopy) yang dilanjutkan dengan melakukan pengujian kekerasan.

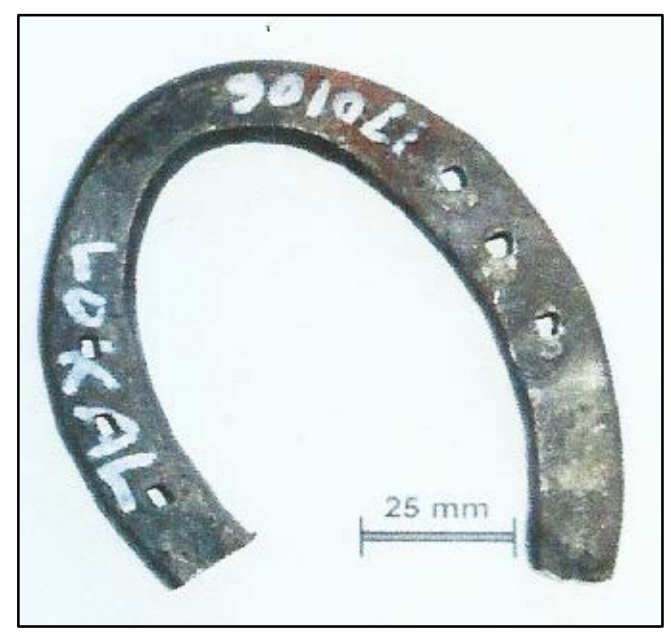

(a)

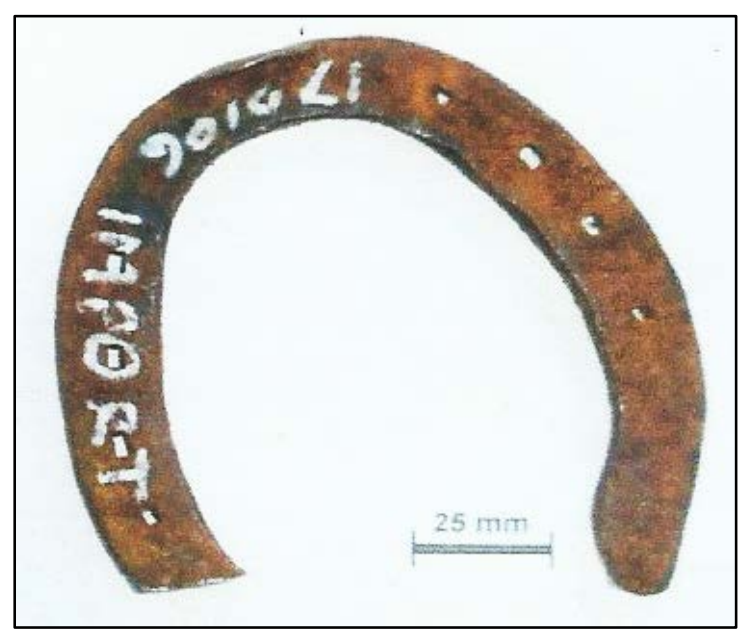

(b)

Gambar 1. Produk ladam. (a). Lokal (Sukabumi) dan (b). Impor (Australia)

\section{HASIL DAN PEMBAHASAN}

Komposisi kimia produk ladam lokal dan impor dapat dilihat pada Gambar 1. Kadar karbon produk lokal adalah 0,17\% sedangkan produk impor sebesar 0,087\%. Sementara itu, tidak diperoleh unsur paduan lain karena harga paduan-paduan seperti $\mathrm{Ni}$, $\mathrm{Cr}$ dan Mo nilainya rendah. Dapat dipastikan bahwa pengrajin memperoleh baja tersebut berasal dari baja karbon rendah termasuk 
kategori St-37 yaitu baja yang sering ditemui untuk keperluan sehari-hari seperti untuk tulangan beton dan pagar. Kadar Sulfur dan phosfor masing-masing berkisar 0,05\%, ini merupakan jumlah prosentase yang umum walaupun menurut standar untuk baja-baja struktur disyaratkan maksimum sebesar 0,03\%. Diduga kadar mangan ditujukan untuk mengimbangi nilai sulfur agar tidak terjadi fenomena hot shortness pada saat proses pengerjaan panas. Hal ini terbukti dengan besarnya rasio mangan terhadap sulfur minimum sebesar 8. Lain halnya dengan ladam impor dimana kadar karbon yang diuji setengah kalinya produk lokal. Kadar Sulfur dan Fosfor produk impor memenuhi standar yaitu dibawah 0,03\%. Dengan demikian, maka ladam impor lebih bersih dari sisi inklusi dibandingkan dengan produk lokal.

Struktur mikro produk ladam lokal dan impor dapat dilihat pada Gambar 3. Dari struktur mikro nampak bahwa jumlah perlit (hitam) pada produk impor lebih sedikit dibandingkan dengan produk lokal. Hal ini menunjukkan bahwa kadar karbon ladam lokal lebih tinggi dibandingkan dengan ladam impor (Gambar 2). Fasa ferit pada ladam impor lebih kasar dan memanjang serta ditandai dengan adanya struktur Widmanstaten. Hal ini menunjukkan bahwa ladam impor dipanaskan hingga temperatur austenisasi yang relatif tinggi dan dengan waktu yang cukup lama kemudian dilakukan deformasi plastis.

\begin{tabular}{|c|c|c|c|c|}
\hline \multicolumn{5}{|c|}{ SPEKTROMETER EMISI OPTIK } \\
\hline \multirow[t]{10}{*}{ Foto benda Uji : } & No & Unsur / Eleme & & Nilai (\%) \\
\hline & 1 & Carbon & (C) & 0,170 \\
\hline & 2 & Silicon & ( $\mathrm{Si}$ ) & 0,237 \\
\hline & 3 & Sulfur & (S) & 0,047 \\
\hline & 4 & Phosphorus & (P) & 0,051 \\
\hline & 5 & Manganese & $(\mathrm{Mn})$ & 0,579 \\
\hline & 6 & Nickel & $(\mathrm{Ni})$ & 0,09 \\
\hline & 7 & Chromium & $(\mathrm{Cr})$ & 0,07 \\
\hline & 8 & Molybdenum & (Mo) & 0,018 \\
\hline & \multicolumn{4}{|c|}{ (a) } \\
\hline
\end{tabular}

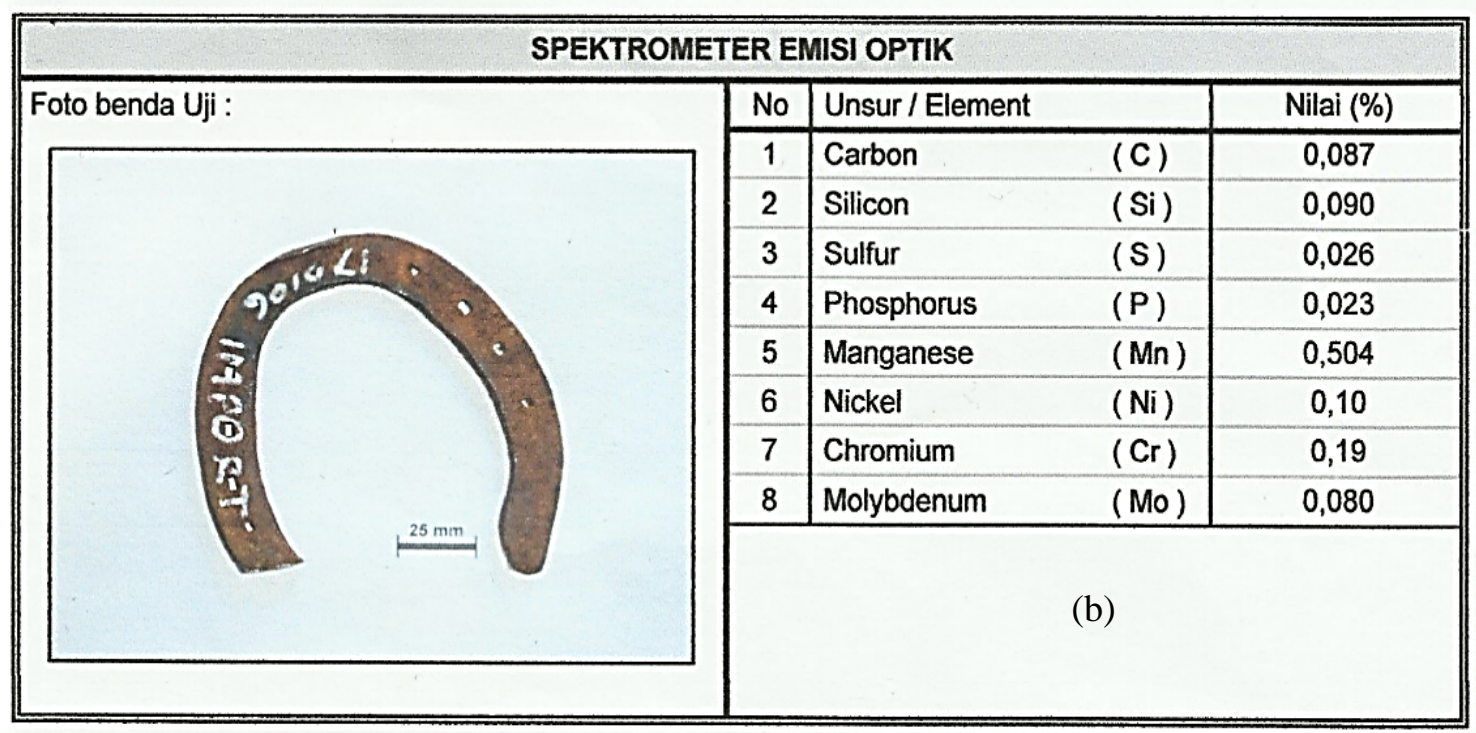

Gambar 2. Komposisi kimia produk ladam (a). Produk lokal dan (b). Produk impor 


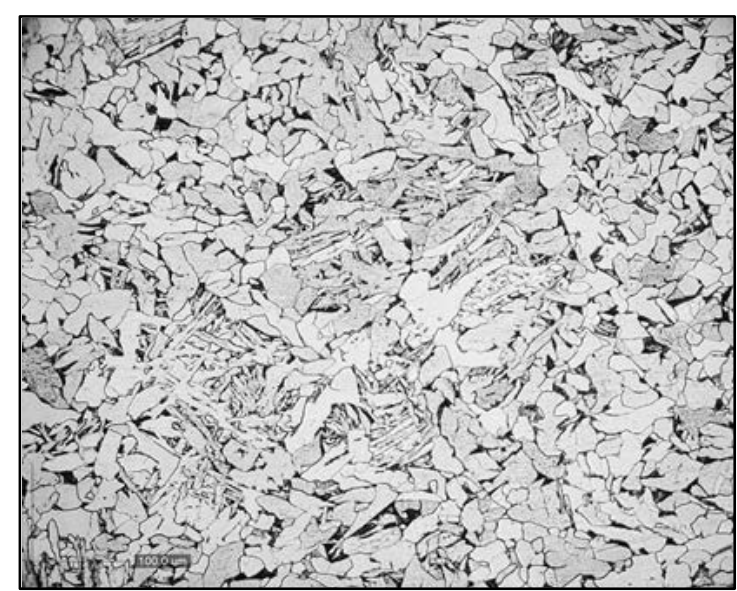

(a)

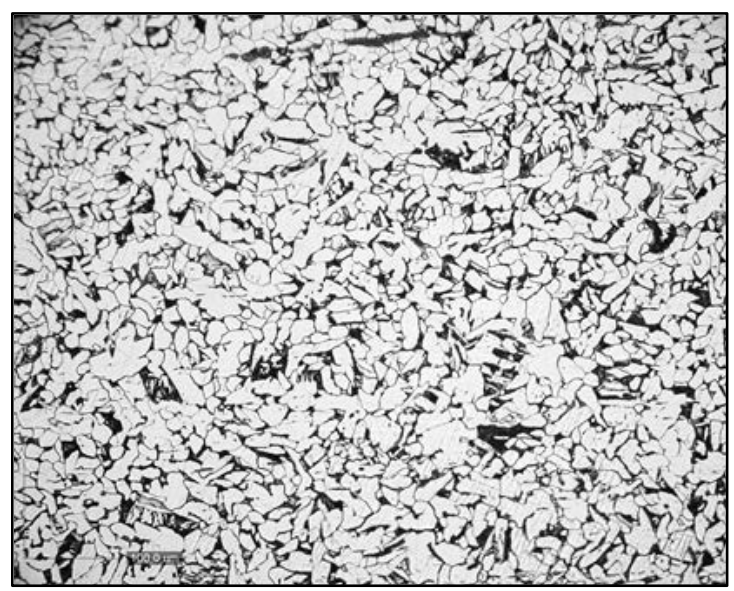

(b)

Gambar 3. Struktur mikro ladam (a). Produk lokal dan (b). Produk impor

Dari hasil pengujian kekerasan diperoleh bahwa nilai kekerasan rata-rata (3 kali pengujian) untuk ladam lokal adalah sebesar 141 BHN sedangkan ladam impor sebesar 185 BHN. Hal ini menunjukkan bahwa sekalipun kadar karbon ladam impor lebih rendah namun derajat deformasinya relatif lebih tinggi dibandingkan dengan ladam lokal. Ketiga hasil pengamatan (komposisi kimia, struktur mikro, dan harga kekerasan) di atas saling berkaitan sehingga memperkuat analisis identifikasi material ladam. Nilai kekerasan ladam lokal sebesar itu sesuai dengan nilai kekerasan baja karbon yang umum. Dengan demikian, maka benarlah bahwa ladam lokal yang dibuat di pengrajin termasuk ke dalam kategori baja karbon rendah St-37.

\section{SIMPULAN}

Beberapa hal yang dapat disimpulkan dari hasil penelitian ini adalah: 1). Ladam lokal termasuk kedalam kategori baja karbon rendah St-37, 2). Ladam impor memiliki kadar karbon yang relatif lebih rendah yaitu setengah kali ladam lokal dan 3). Ladam impor telah mengalami proses pemasanasan pada temperatur austenisasi yang cukup tinggi dan waktu yang cukup lama kemudian dilakukan deformasi plastis.

Perlu dilakukan pengamatan lanjut pada material dengan komposisi kimia sesuai dengan ladam impor. Agar dilakukan proses pemanasan dan deformasi plastis pada material di atas sehingga memiliki karakteristik sesuai dengan ladam impor, dilakukan penelitian pengamatan fleksibilitas ladam impor serta dikembangkan metode proses manufaktur ladam seperti ladam impor.

\section{UCAPAN TERIMA KASIH}

Ucapan terima kasih yang sebesar-besarnya disampaikan kepada Dirjen Pendidikan Tinggi Penelitian Hibah Bersaing tahun 2017 yang telah memberikan bantuan dana bagi terlaksananya penelitian ini. Sejujurnya disampaikan pula bahwa kelancaran berlangsungnya penelitian ini berkat perhatian tulus sejumlah pribadi yang amat antusias dalam pencapaian tujuan penelitian dalam perbaikan komponen yang terbuat dari paduan Aluminium.

\section{DAFTAR PUSTAKA}

[1]. Ball, M.A., 2000, Understanding Basic Horse Health Care, Lexington: The Blood-Horse, Inc.

[2]. Back, W., 2001, The Role of the Hoof and Shoeing, Edinburgh, UK: Saunders Ldt.

[3]. García, C., 2013, Structural Material Investigation of Horse Hoof, Skövde: University of Skövde. 
[4]. Barrey, E., 1990, Investigation of the vertical hoof force distribution in the equine forelimb with an instrumented horse boot, Equine Veterinary Journal Supplement, 35-38.

[5]. Data Penggunaan Sepatu Kuda Pacu di Jawa Barat (2015).

[6]. W.M.E. Wattimena, Jandri Louhenapessy, 2014, Pengaruh Holding Time Dan Quenching Terhadap Kekerasan Baja Karbon St 37 Pada Proses Pack Carburizing Menggunakan Arang Batok Biji Pala (Myristica Fagrans). Jurnal Ilmu-ilmu Teknik dan Sains, Vol. 11 No. 1, April 2014

[7]. Hinterhofer, C., Stanek, C. and Haider, H., 2001, Finite Element Analysis (FEA) as a Model to Predict Effects of Farriery on the Equine Hoof, Equine Veterinary Journal, 58-62. 